\title{
Sistemas conservacionistas de manejo do solo para amendoim cultivado em sucessão à cana crua
}

\author{
Denizart Bolonhezi(1), Miguel Ângelo Mutton ${ }^{(2)}$ e Antonio Lúcio Mello Martins ${ }^{(3)}$
}

\begin{abstract}
(1) Agência Paulista de Tecnologia dos Agronegócios (APTA), Centro Leste, Avenida Bandeirantes, no 2419, CEP 14030-670 Ribeirão Preto, SP. E-mail: denizart@aptaregional.sp.gov.br (2)Universidade Estadual Paulista, Fac. de Ciências Agrárias e Veterinárias, CEP 14884-900 Jaboticabal, SP. E-mail: miguelmutton@fcav.unesp.br (3)APTA, Centro Norte, Rod. Washignton Luiz, Km 372, Caixa Postal 24, CEP 15830-000 Pindorama, SP. E-mail: Imartins@aptaregional.sp.gov.br
\end{abstract}

Resumo - Com o objetivo de avaliar o efeito de sistemas conservacionistas de manejo do solo sobre características agronômicas de cultivares de amendoim com hábitos de crescimento contrastantes, foram instalados sete ensaios de campo; seis em Latossolo Vermelho eutroférrico (Ribeirão Preto, SP) e um em Argissolo Vermelho-Amarelo (Pindorama, SP), todos em renovação de canaviais colhidos sem queima prévia. Utilizou-se o delineamento de blocos ao acaso, com os tratamentos arranjados em esquema de parcelas subdivididas e quatro repetições. Os tratamentos principais foram os sistemas de manejo - convencional, cultivo mínimo e plantio direto - e os secundários, as cultivares IAC-Tatu ST e IAC-Caiapó. Não há diferença estatística para produção de vagens e grãos e número de estruturas reprodutivas, entre manejos conservacionistas e convencional, porém pode haver redução no estande final de plantas. Em três dos sete ensaios houve interação significativa entre cultivar e sistema de manejo. A cultivar IAC-Caiapó é menos responsiva às diferenças de manejo do solo. O plantio direto pode proporcionar aumento de 6,5 a $9 \%$ no índice de rendimento de grãos e apresentar maior conteúdo de água no solo em período de seca.

Termos para indexação: Arachis hypogaea, plantio direto, cultivo mínimo, palha de cana, cultivares.

\section{Conservation tillage to peanut crop in rotation with green harvest sugarcane}

\begin{abstract}
Field studies were conducted from 2000 to 2005 to evaluate the effects of conservation tillage on agronomic characteristics of two peanut cultivars, cultivated in rotation with sugarcane harvested without burning. Tillage systems included reduced tillage, no-tillage, and conventional tillage, which were arranged in a split-plot randomized complete block design with four replications in two different types of soil, Oxisol and Ultisol, located in Ribeirão Preto and Pindorama cities, SP, Brazil. Tillage treatments were main plots while subplots were peanut genotypes (IAC-Tatu ST and IAC-Caiapó). Results of seven experiments showed no statistic difference on pod yield, kernel yield, number of pods and pegs, between the conservation tillage systems and the conventional tillage, but a decrease on stand of plants can occur. Three out of seven experiments showed a significant interaction between the cultivar and tillage system. The response of different tillage systems for cv. IAC-Caiapó was lower than for cv. IAC-Tatu ST. No-tillage system can show increase (between 6.5 and $9 \%$ ) on mature kernel rate as well as good or better soil moisture during a dry period.
\end{abstract}

Index terms: Arachis hypogaea, no-tillage, minimum-tillage, sugarcane straw, cultivars.

\section{Introdução}

A produção de amendoim no Brasil está concentrada no Estado de São Paulo, que detém $87 \%$ da quantidade produzida e $77 \%$ da área cultivada, na maioria das vezes como cultura de sucessão na renovação de canaviais, basicamente praticada por agricultores arrendatários (Bolonhezi et al., 2005).

Esta oleaginosa apresenta boas perspectivas de retomar o destaque que teve na década de 70 , quando a área de cultivo era aproximadamente dez vezes maior que a atual, em decorrência da expansão da canavicultura e da utilização do biodiesel. Nas safras 2003/2004 e 2004/2005 foram destinados para reforma de cana-de-açúcar, respectivamente, 431 e 275 mil ha de canaviais, de acordo com imagens de satélite (Rudorff et al., 2004) que, em boa parte, estão disponíveis para o cultivo de amendoim na entressafra da cultura canavieira. 
A legislação vigente (Decreto de Lei Estadual 47.700, de 11/3/2003, que regulamenta a Lei Estadual 11.241, de 19/9/2002) determina a eliminação gradativa das queimadas e forçará o aumento da adoção da colheita mecanizada de cana-de-açúcar sem queima prévia, que é realizada em mais de $30 \%$ dos canaviais paulistas (Ripoli \& Ripoli, 2004). Nesse sistema de colheita, são depositados sobre a superfície do solo em média $15 \mathrm{Mg} \mathrm{ha}^{-1}$ de matéria seca de palhiço, que em virtude de alta recalcitrância, modificou as práticas culturais usuais no canavial, sobretudo o preparo do solo por ocasião da renovação. A adoção de manejo conservacionista nessas condições proporciona redução de $30 \%$ no custo de preparo do solo.

A semeadura direta é utilizada em larga escala no cultivo de soja sobre cana crua, mas pouco se conhece sobre a viabilidade dessa prática na cultura do amendoim.

As peculiaridades morfofisiológicas da planta de amendoim, cujas estruturas reprodutivas se desenvolvem em subsuperfície, conduzem ao mito técnico de que o preparo do solo é essencial para viabilizar o cultivo comercial (Sholar et al., 1995). Todavia, mesmo a escarificação da entrelinha ou a amontoa, preconizada por muitos anos, além de não resultar em aumentos de produção, podem aumentar a incidência de patógenos nas vagens (Wright et al., 1986).

Estudos comparativos entre o preparo de solo convencional e sistemas conservacionistas para amendoim vêm sendo conduzidos em outros países desde o final da década de 70. Sob condições norte-americanas, pesquisas verificaram perdas entre 19 e $62 \%$ na produção de vagens e grãos nos sistemas conservacionistas de preparo (Grichar \& Boswell, 1987; Wright \& Porter, 1991; Sholar et al., 1995). Os resultados desfavoráveis são atribuídos à dificuldade no controle de plantas daninhas, aos problemas de compactação do solo (Colvin et al., 1988) e à maior incidência de doenças nas vagens (Jordan et al., 2001). Por sua vez, existem relatos sobre resultados favoráveis aos sistemas conservacionistas, ou sem diferença significativa, com indicação da possibilidade de obtenção de produções comerciais com aumentos de até 10\% (Hartzog \& Adams, 1989; Wright, 1991; Grichar, 1998).

Os resultados de produção podem (Grichar \& Smith, 1991) ou não depender das características de porte das cultivares de amendoim (Colvin \& Brecke, 1988; Grichar \& Smith 1992). Além disso, deve-se considerar que nos sistemas conservacionistas podem ocorrer diminuição da incidência de Cercospora arachidicola (Porter \& Wright, 1991), redução de danos ocasionados por ataque do tripes e pela incidência de virose TSWV, manutenção da umidade do solo e redução do custo de produção (Scholar et al., 1995).

O objetivo deste trabalho foi avaliar a influência de sistemas de manejo do solo sobre algumas características agronômicas de duas cultivares de amendoim, com hábito de crescimento contrastante, em sucessão a canavial colhido sem queima prévia ou cana crua.

\section{Material e Métodos}

Este trabalho constou de experimentação conduzida em campo, durante os anos agrícolas 1999/2000, 2000/2001, 2001/2002, 2002/2003, 2003/2004, 2004/2005, em Ribeirão Preto, SPe no ano 2000/2001, em Pindorama, SP. Os locais de condução compreendem as antigas estações experimentais do Instituto Agronômico, atualmente denominadas APTA - Centro Leste (Ribeirão Preto), situada a $21^{\circ} 11^{\prime} \mathrm{S} 47^{\circ} 93^{\prime} \mathrm{W}$ e APTA - Centro Norte (Pindorama), situada a $48^{\circ} 55^{\prime} \mathrm{W}$ e $21^{\circ} 13^{\prime} \mathrm{S}$.

O clima dos dois locais, segundo classificação de Köppen, é do tipo CWa, com pluviosidade média anual de 1.427 e $1.258 \mathrm{~mm}$, temperatura máxima de $25 \mathrm{e}$ $23,8^{\circ} \mathrm{C}$, temperatura mínima de 19 e $19,3^{\circ} \mathrm{C}$, altitude média de 646 e 594 m, respectivamente, para Ribeirão Preto e Pindorama. Conforme sistema brasileiro de classificação de solos (Embrapa, 1999), o solo de Ribeirão Preto está classificado como Latossolo Vermelho eutroférrico, textura argilosa; enquanto o de Pindorama está classificado como Argissolo VermelhoAmarelo, eutrófico, textura fina arenosa e extremamente susceptível à erosão hídrica.

Todos os sete ensaios foram instalados com delineamento experimental em blocos ao acaso, com os tratamentos arranjados em esquema de parcelas subdivididas, com quatro repetições no campo. Os tratamentos principais consistiram dos três sistemas de preparo; convencional (grade + arado de aivecas + gradagens niveladoras), cultivo mínimo (dessecação da soqueira com $2.400 \mathrm{~g} \mathrm{ha}^{-1}$ de i.a. de glifosate + arado subsolador com cinco hastes e rolo destorroador, modelo ASTMATIC 450 - Tatu Marchesan) e plantio direto (dessecação da soqueira).

Os tratamentos secundários foram compostos pelas cultivares de amendoim IAC-Tatu ST (porte ereto e ciclo de 90 a 100 dias) e IAC-Caiapó (porte rasteiro e ciclo de 135 dias). Quanto à cultivar IAC-Tatu ST, adotou-se espaçamento 0,60 m entre as linhas e densidade de 22 sementes por metro. Para a cultivar IAC-Caiapó, adotou-se espaçamento $0,9 \mathrm{~m}$ entre linhas e densidade 
de 15 sementes por metro. Utilizou-se semeadora pneumática modelo Exacta 2900 - Jumil, em Ribeirão Preto, e modelo Exacta 2600, em Pindorama, ambas com disco desencontrado na distribuição do adubo.

Na Tabela 1, encontram-se as características químicas do solo e a quantidade de palhiço. Embora o índice de saturação por bases (V\%) indicasse necessidade de calagem, não foi aplicado calcário, a fim de não incluir outra causa de variação. As adubações foram efetuadas para atingir produtividades de $3.000 \mathrm{~kg} \mathrm{ha}^{-1}$. Em todos os ensaios, foram fornecidos $24 \mathrm{~kg} \mathrm{ha}^{-1} \mathrm{de} \mathrm{N}, 84 \mathrm{~kg} \mathrm{ha}^{-1}$ de $\mathrm{P}_{2} \mathrm{O}_{5}$ e $48 \mathrm{~kg} \mathrm{ha}^{-1}$ de $\mathrm{K}_{2} \mathrm{O}$, por meio da fórmula 8-28-16, sem uso de inoculantes e micronutrientes. Na Tabela 2, estão especificadas as datas dos principais eventos, pluviosidade e períodos de deficiência hídrica.

$\mathrm{O}$ arranquio e a colheita foram manuais, quando aproximadamente $75 \%$ das vagens encontravam-se maduras. Foram colhidas todas as plantas presentes em 4 linhas de $5 \mathrm{~m}$, em três pontos por subparcela, nas quais foram determinadas: produção de vagem e grãos, estande final de plantas, índice de rendimento (IR) de grãos e número de estruturas reprodutivas por planta. O conteúdo volumétrico de água $(\%)$ no solo foi quantificado no ensaio 2003/2004, com utilização TDR (modelo Hydrosense, Campbell Scientific). As leituras foram feitas em diferentes fases do desenvolvimento da cultura e posição de medida, nas profundidades de $0,00-0,12$ e $0,00-0,20 \mathrm{~m}$. Os resultados obtidos foram submetidos à análise da variância e as médias comparadas pelo teste de Tukey, a 5\% de probabilidade, com a utilização do SAS.

\section{Resultados e Discussão}

Ocorreu interação significativa entre sistemas de manejo do solo e cultivares de amendoim para variável produção de vagens, em três dos sete ensaios conduzidos (1999/2000, 2001/2002 em Ribeirão Preto e 2000/2001 em Pindorama) (Tabela 3). Nos demais anos, quanto à média das cultivares, não houve diferença $(\mathrm{p} \geq 0,05)$ entre os sistemas de manejo, o que corrobora os resultados de Colvin \& Brecke (1988) e Grichar \& Smith (1992), referentes às condições norte-americanas, os quais esclarecem que a resposta aos níveis de revolvimento do solo independem do tipo de ramificação, alternada (Virgínia) ou seqüencial ("Spanish" e Valência). Embora existam resultados para condições semelhantes às deste trabalho, que mencionam aumentos significativos na produção de vagens, quando se adota sistemas conservacionistas (Tasso Júnior, 2003), a predominância de anos sem diferença estatística também é encontrada em pesquisas de longa duração (Hartzog \& Adams, 1989; Grichar, 1998).

Por meio do desdobramento das interações (Figura 1), observa-se que a produção de vagens foi significativamente maior nos sistemas conservacionistas, para a cultivar

Tabela 1. Características químicas dos solos das áreas dos experimentos conduzidos em Ribeirão Preto e Pindorama, referentes à profundidade de $0,00-0,20 \mathrm{~m}$.

\begin{tabular}{|c|c|c|c|c|c|c|c|c|c|c|c|c|}
\hline Local & Ano & $\begin{array}{c}\mathrm{MS} \\
\left(\mathrm{t} \mathrm{ha}^{-1}\right)\end{array}$ & $\begin{array}{c}\mathrm{pH} \\
\mathrm{CaCl}_{2}\end{array}$ & $\begin{array}{c}\mathrm{MO} \\
\left(\mathrm{g} \mathrm{dm}^{-3}\right)\end{array}$ & $\begin{array}{c}\mathrm{P} \\
\left(\mathrm{mg} \mathrm{dm}^{-3}\right)\end{array}$ & K & $\mathrm{Ca}$ & $\begin{array}{l}\mathrm{Mg} \\
--(\mathrm{m}\end{array}$ & $\begin{array}{r}\mathrm{H}+\mathrm{Al} \\
\left.\mathrm{dm}^{-3}\right)--\end{array}$ & SB & CTC & $\begin{array}{c}\mathrm{V} \\
(\%)\end{array}$ \\
\hline \multirow[t]{6}{*}{ Ribeirão Preto } & $1999 / 2000$ & 9,3 & 4,7 & 28 & 20 & 1,2 & 15 & 4,3 & 54 & 20,2 & 74,3 & 27 \\
\hline & $2000 / 2001$ & 8,7 & 4,6 & 29 & 38 & 0,9 & 14 & 3,6 & 63 & 18,4 & 81,8 & 23 \\
\hline & $2001 / 2002$ & 9,5 & 5,1 & 25 & 18 & 1,1 & 25 & 10 & 39 & 36,1 & 75,1 & 48 \\
\hline & $2002 / 2003$ & 10,6 & 5,0 & 32 & 41 & 2,9 & 24 & 8 & 42 & 34,9 & 77,2 & 45 \\
\hline & $2003 / 2004$ & 17,0 & 5,2 & 32 & 28 & 0,8 & 26 & 16 & 38 & 42,8 & 80,9 & 53 \\
\hline & $2004 / 2005$ & 11,0 & 5,0 & 31 & 36 & 1,3 & 27 & 7 & 48 & 35,3 & 83,6 & 42 \\
\hline Pindorama & $2000 / 2001$ & 6,3 & 4,9 & 7 & 3 & 3,6 & 12 & 2 & 18 & 17,6 & 35,8 & 49 \\
\hline
\end{tabular}

Tabela 2. Datas de semeadura dos experimentos conduzidos em Ribeirão Preto e Pindorama e quantidade acumulada de chuva (mm) no período.

\begin{tabular}{|c|c|c|c|c|c|c|c|}
\hline \multirow[t]{2}{*}{ Evento } & \multicolumn{6}{|c|}{ Ribeirão Preto } & \multirow{2}{*}{$\begin{array}{l}\text { Pindorama } \\
2000 / 2001 \\
\end{array}$} \\
\hline & $1999 / 2000$ & $2000 / 2001$ & $2001 / 2002$ & $2002 / 2003$ & $2003 / 2004$ & $2004 / 2005$ & \\
\hline Semeadura & $18 / 1 / 2000$ & $28 / 11 / 2000$ & $20 / 12 / 2001$ & $12 / 11 / 2002$ & $2 / 12 / 2003$ & $1 / 12 / 2004$ & $12 / 1 / 2001$ \\
\hline Emergência & $25 / 1 / 2000$ & $5 / 12 / 2000$ & $26 / 12 / 2001$ & $19 / 11 / 2002$ & $9 / 12 / 2003$ & $10 / 12 / 2004$ & $18 / 1 / 2001$ \\
\hline Colheita da cv. IAC-Tatu ST & $26 / 5 / 2000$ & $16 / 3 / 2001$ & $17 / 4 / 2002$ & $21 / 2 / 2003$ & $18 / 3 / 2004$ & $8 / 3 / 2005$ & $28 / 4 / 2001$ \\
\hline Colheita da cv. IAC-Caiapó & $26 / 6 / 2000$ & $17 / 4 / 2001$ & $13 / 5 / 2002$ & $25 / 3 / 2003$ & $20 / 4 / 2004$ & $25 / 4 / 2005$ & $18 / 6 / 2001$ \\
\hline Chuva (mm) & 458,7 & 791,4 & 979,2 & $1.252,8$ & $1.130,2$ & $1.117,9$ & 646,2 \\
\hline \multirow[t]{2}{*}{ Deficiência hídrica (mm) } & Abril: $-85,8$ & Janeiro: $-58,3$ & Abril: $-89,8$ & & Março: $-30,1$ & Fevereiro: $-72,8$ & Fevereiro: $-77,7$ \\
\hline & Maio: $-67,1$ & Abril: $-21,7$ & Maio: $-22,2$ & & & Março: $-65,7$ & Abril: $-46,9$ \\
\hline
\end{tabular}


Tabela 3. Produção de vagens $\left(\mathrm{kg} \mathrm{ha}^{-1}\right)$ de duas cultivares de amendoim, em três sistemas de manejo do solo, em Ribeirão Preto e Pindorama ${ }^{(1)}$.

\begin{tabular}{|c|c|c|c|c|c|c|c|}
\hline \multirow[t]{2}{*}{ Sistema (S) } & \multicolumn{6}{|c|}{ Ribeirão Preto } & \multirow{2}{*}{$\begin{array}{l}\text { Pindorama } \\
2000 / 2001\end{array}$} \\
\hline & $1999 / 2000$ & $2000 / 2001$ & $2001 / 2002$ & $2002 / 2003$ & $2003 / 2004$ & $2004 / 2005$ & \\
\hline Convencional & 1.746 & 3.520 & 2.385 & 2.433 & 5.025 & 2.978 & 3.133 \\
\hline Cultivo mínimo & 1.849 & 3.267 & 2.258 & 2.379 & 4.672 & 3.272 & 2.730 \\
\hline Plantio direto & 1.881 & 3.010 & 2.343 & 2.663 & 5.102 & 3.167 & 2.534 \\
\hline Teste F & $0,53^{\mathrm{ns}}$ & $3,10^{\mathrm{ns}}$ & $0,17^{\mathrm{ns}}$ & $1,47^{\mathrm{ns}}$ & $1,07^{\mathrm{ns}}$ & $1,79^{\mathrm{ns}}$ & $4,31^{\mathrm{ns}}$ \\
\hline dms (Tukey, 5\%) & 421 & 629 & 672 & 538 & 961 & 481 & 745 \\
\hline \multicolumn{8}{|l|}{ Cultivar (C) } \\
\hline IAC-Tatu ST & $1.735 b$ & $3.097 \mathrm{~b}$ & $2.422 \mathrm{a}$ & $2.226 \mathrm{~b}$ & 4.775 & $2.580 \mathrm{~b}$ & $2.951 \mathrm{a}$ \\
\hline IAC-Caiapó & $1.917 \mathrm{a}$ & $3.434 \mathrm{a}$ & $2.234 \mathrm{~b}$ & $2.757 \mathrm{a}$ & 5.092 & $3.698 \mathrm{a}$ & $2.647 \mathrm{~b}$ \\
\hline Teste F & $9,62 *$ & $9,3^{*}$ & $6,31 *$ & $41,3 * *$ & $4.62^{\mathrm{ns}}$ & $102 * *$ & $5,09 *$ \\
\hline dms (Tukey, 5\%) & 132 & 249 & 202 & 186 & 333 & 249 & 638 \\
\hline \multicolumn{8}{|l|}{ Interação S x C } \\
\hline Teste F & $6,89^{*}$ & $0,1^{\mathrm{ns}}$ & $16,4 * *$ & $1,93^{\mathrm{ns}}$ & $0,20^{\mathrm{ns}}$ & $1,03^{\mathrm{ns}}$ & $1,85^{*}$ \\
\hline $\mathrm{CV}(\%)$ parcela & 15,0 & 12,5 & 18,8 & 14,1 & 12,7 & 9,9 & 14,9 \\
\hline CV (\%) subparcela & 7,9 & 8,3 & 7,9 & 8,1 & 7,3 & 8,6 & 11,7 \\
\hline
\end{tabular}

(1) As letras comparam médias dentro de cada ano de condução. ns Não-significativo. * e ** Significativo a 5 e $1 \%$ de probabilidade, respectivamente.
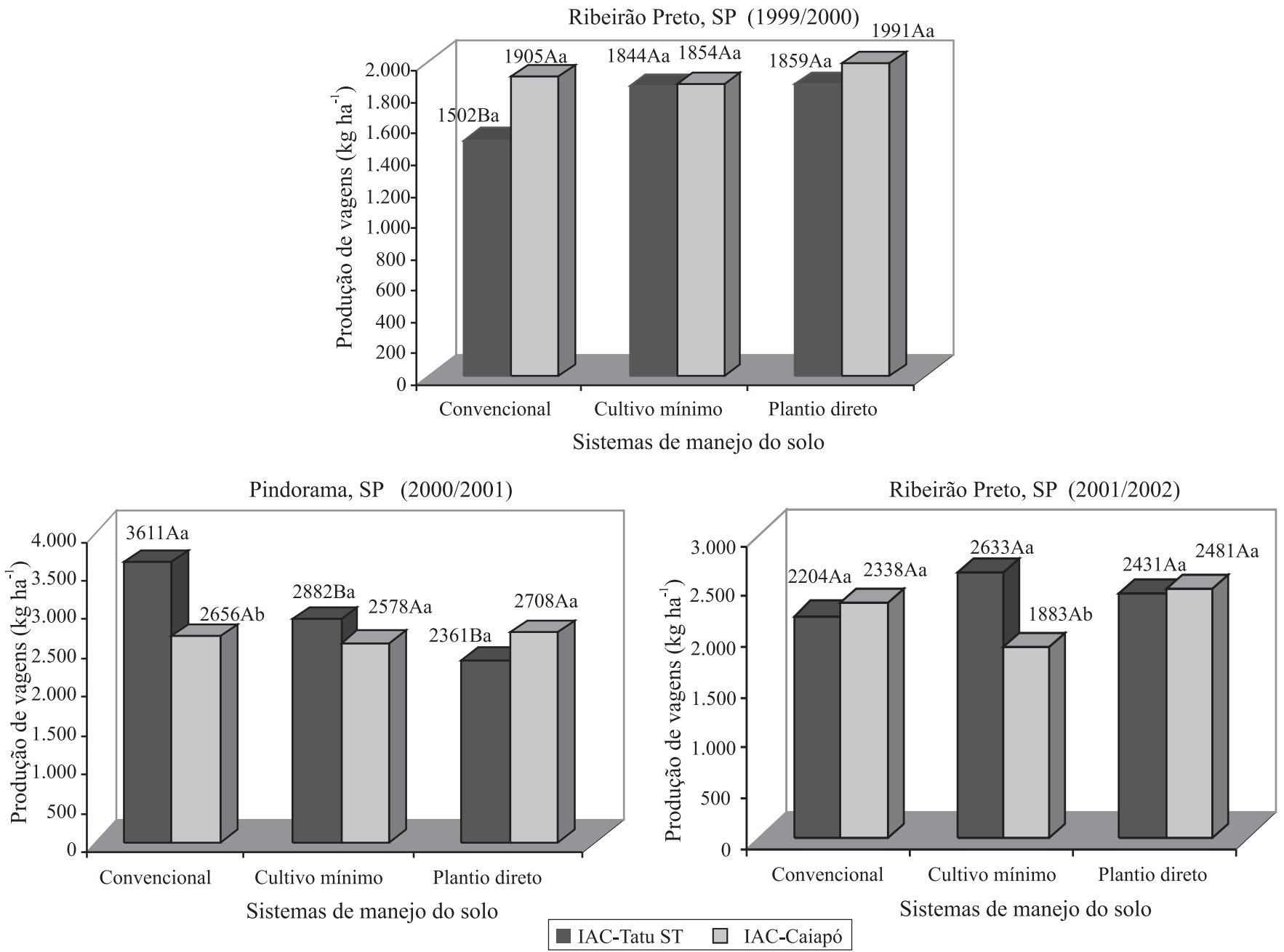

Figura 1. Desdobramentos das interações entre sistemas de manejo e cultivares de amendoim, para produção de vagens. Ensaios de Ribeirão Preto, anos 1999/2000 e 2001/2002 e Pindorama 2000/2001. Letras maiúsculas comparam médias entre sistemas e letras minúsculas, entre cultivares, a 5\% de probabilidade, pelo teste de Tukey. 
IAC-Tatu ST no ano 1999/2000, enquanto para a IAC-Caipó, não houve diferença estatística entre os manejos, em semeadura extemporânea. Pode-se inferir que o palhiço de cana crua contribuiu para reduzir a perda de água nos períodos de deficiência hídrica (Tabela 2). Entretanto, em Pindorama (2000/2001), ocorreu o inverso para a cultivar IAC-Tatu ST. Para a IAC-Caiapó, nos dois ensaios, não houve diferença estatística entre os sistemas de manejo, o que indica que uma cultivar de porte rasteiro e ciclo longo é menos responsiva às variações de preparo. No ensaio de Ribeirão Preto, em 2001/2002, não foram observadas diferenças estatísticas entre os sistemas, porém a cultivar IAC-Caiapó produziu menos que a IAC-Tatu ST no cultivo mínimo.
Com relação à produção de grãos, observa-se (Tabela 4) que para a média das cultivares, em semeadura tardia (1999/2000) o sistema convencional de manejo produziu cerca de $30 \%$ menos que o sistema plantio direto. Todavia, a interação entre genótipos e manejos do solo se manteve significativa nos ensaios de 2001/2002 em Ribeirão Preto e em Pindorama e corrobora os resultados de Grichar \& Smith (1991), os quais concluíram que há forte interação entre genótipo e sistema de manejo. As diferenças entre sistemas foram as mesmas que ocorreram na produção de vagens (Figura 2). A cultivar IAC-Caiapó produziu significativamente mais grãos no sistema plantio direto,

Tabela 4. Produção de grãos $\left(\mathrm{kg} \mathrm{ha}^{-1}\right)$ de duas cultivares de amendoim, em três sistemas de manejo do solo, em Ribeirão Preto e Pindorama ${ }^{(1)}$.

\begin{tabular}{|c|c|c|c|c|c|c|c|}
\hline \multirow[t]{2}{*}{ Sistema (S) } & \multicolumn{6}{|c|}{ Ribeirão Preto } & \multirow{2}{*}{$\begin{array}{l}\text { Pindorama } \\
2000 / 2001\end{array}$} \\
\hline & $1999 / 2000$ & $2000 / 2001$ & $2001 / 2002$ & $2002 / 2003$ & $2003 / 2004$ & $2004 / 2005$ & \\
\hline Convencional & $1.054 \mathrm{~b}$ & 2.579 & 1.629 & 1.640 & 3.444 & 2.042 & $2.112 \mathrm{a}$ \\
\hline Cultivo mínimo & $1.267 \mathrm{ab}$ & 2.431 & 1.596 & 1.692 & 3.286 & 2.164 & $1.724 \mathrm{ab}$ \\
\hline Plantio direto & $1.350 \mathrm{a}$ & 2.231 & 1.623 & 1.968 & 3.616 & 2.089 & $1.522 \mathrm{~b}$ \\
\hline Teste F & $5,55^{*}$ & $2,46^{\mathrm{ns}}$ & $0,03^{\mathrm{ns}}$ & $3,0^{\mathrm{ns}}$ & $0,82^{\mathrm{ns}}$ & $1,33^{\mathrm{ns}}$ & $6,2 *$ \\
\hline dms (Tukey, 5\%) & 282 & 484 & 438 & 471 & 790 & 232 & 521 \\
\hline \multicolumn{8}{|l|}{ Cultivar (C) } \\
\hline IAC-Tatu ST & 1.168 & $2.274 b$ & 1.638 & $1.592 \mathrm{~b}$ & $3.630 \mathrm{~b}$ & $1.731 \mathrm{~b}$ & 1.853 \\
\hline IAC-Caiapó & 1.279 & $2.552 \mathrm{a}$ & 1.594 & $1.910 \mathrm{a}$ & $3.268 \mathrm{a}$ & $2.466 \mathrm{a}$ & 1.719 \\
\hline Teste F & $3,64^{\mathrm{ns}}$ & $9,9^{*}$ & $0,55^{\mathrm{ns}}$ & $6,86^{\mathrm{ns}}$ & $15,8^{* *}$ & $51,7 * *$ & $1,2^{\text {ns }}$ \\
\hline dms (Tukey, $5 \%$ ) & 132 & 199 & 132 & 274 & 205 & 231 & 276 \\
\hline \multicolumn{8}{|l|}{ Interação S x C } \\
\hline Teste F & $3,10^{\mathrm{ns}}$ & $0,01^{\mathrm{ns}}$ & $9,23 * *$ & $0,62^{\mathrm{ns}}$ & $0,15^{\mathrm{ns}}$ & $1,43^{\mathrm{ns}}$ & $4,46^{*}$ \\
\hline $\mathrm{CV}(\%)$ parcela & 15,0 & 13,1 & 17,7 & 17,6 & 14,9 & 7,2 & 19,0 \\
\hline CV (\%) subparcela & 11,7 & 8,8 & 8,9 & 16,9 & 6,5 & 11,9 & 16,8 \\
\hline
\end{tabular}

${ }^{(1)}$ As letras comparam médias dentro de cada ano de condução. ${ }^{\text {ns}}$ Não-significativo. ${ }^{*}$ e ${ }^{* *}$ Significativo a 5 e $1 \%$ de probabilidade, respectivamente.

Ribeirão Preto, SP (2001/2002)

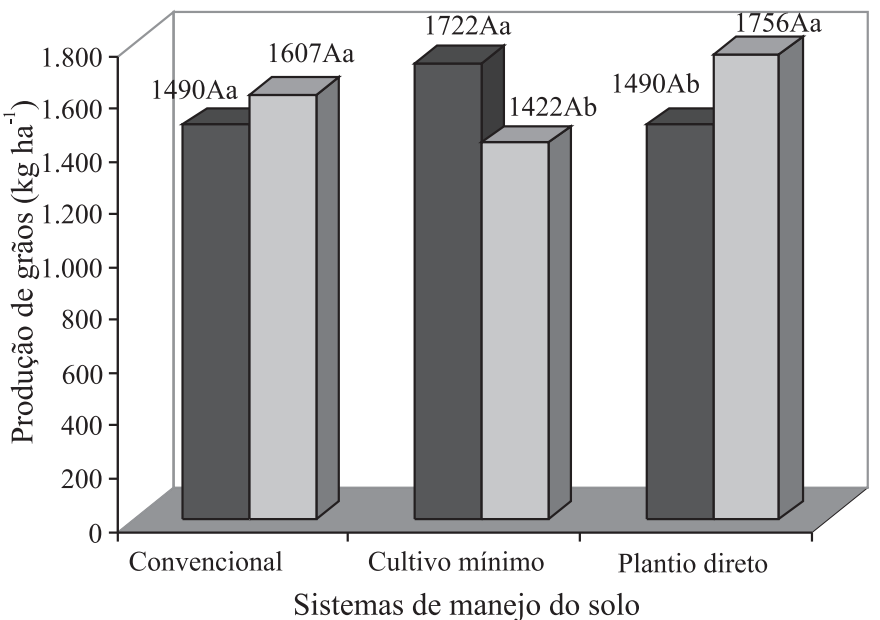

IAC-Tatu ST $\square$ IAC-Caiapó
Pindorama, SP (2000/2001)

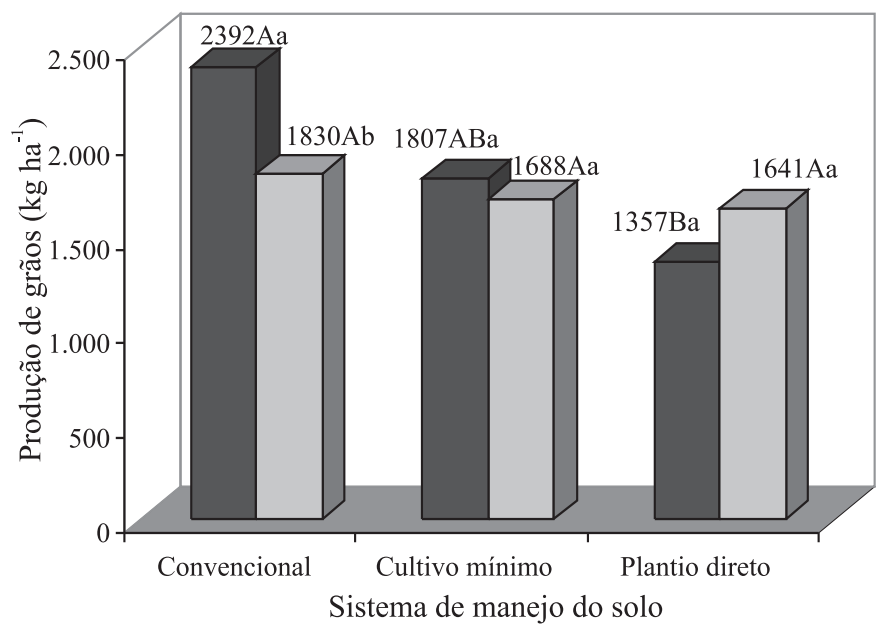

Figura 2. Desdobramentos das interações entre sistemas de manejo do solo e cultivares de amendoim, para produção de grãos. Ensaios de Ribeirão Preto em 2001/2002 e Pindorama em 2000/2001. Letras maiúsculas comparam médias entre sistemas e minúsculas, entre cultivares dentro de cada sistema; letras distintas indicam diferença significativa a 5\% de probabilidade, pelo teste de Tukey. 
no ensaio de Ribeirão Preto, todavia apresentou redução ( $\mathrm{p} \geq 0,05)$ no cultivo mínimo. O mesmo ocorreu em Pindorama no sistema convencional. Embora a IAC-Caiapó apresente maior potencial produtivo, decorrente do maior número de estruturas reprodutivas produzidas, revela desenvolvimento inicial lento, provável razão para o baixo desempenho no cultivo mínimo em Ribeirão Preto. Em sistemas conservacionistas há atraso no desenvolvimento inicial e invariavelmente o momento da colheita deveria ser postergado, em relação ao sistema convencional, pois o arranquio antecipado pode reduzir a produtividade em $15 \%$ e o rendimento em $21 \%$ (Grichar \& Smith, 1991; Wright \& Porter, 1991).

O componente da produção e número de estruturas reprodutivas (vagens e ginóforos) (Tabela 5), auxiliam na explicação das diferenças entre as cultivares. Todavia, o fato de comprovar que a emissão e estabelecimento das estruturas reprodutivas do amendoim não é afetada pela presença de resíduos na superfície ou pela ausência de preparo é um aspecto importante e contradiz as pesquisas que afirmam ser a palhada um fator de impedimento físico à penetração dos ginóforos (Colvin et al., 1988; Wright, 1991).

Oíndice de rendimento de grãos foi 9 e $6,5 \%$ maior $(\mathrm{p} \leq 0,05)$ no sistema plantio direto, em relação ao convencional, respectivamente, nos ensaios de 1999/2000 e 2002/2003 para a média das cultivares (Tabela 6). Somente nos anos 2001/ 2002 e 2003/2004 a cultivar IAC-Caiapó apresentou maior rendimento de grãos que a cultivar IAC-Tatu ST. Estes resultados discordam da maioria das pesquisas publicadas

Tabela 5. Número de estruturas reprodutivas (vagens e ginóforos) em 20 plantas de cultivares de amendoim, submetidas a diferentes sistemas de manejo do solo em renovação de canavial, em Ribeirão Preto. Avaliações realizadas aos 90 (IAC-Tatu ST) e 120 dias após a emergência (IAC-Caiapó) ${ }^{(1)}$.

\begin{tabular}{|c|c|c|c|c|c|c|}
\hline Sistema (S) & $1999 / 2000$ & $2000 / 2001$ & $2001 / 2002$ & $2002 / 2003$ & $2003 / 2004$ & $2004 / 2005^{(2)}$ \\
\hline Convencional & 170 & 387 & 369 & 405 & $499 \mathrm{ab}$ & 297 \\
\hline Cultivo mínimo & 200 & 381 & 363 & 472 & $457 b$ & 340 \\
\hline Plantio direto & 184 & 408 & 372 & 448 & $558 \mathrm{a}$ & 312 \\
\hline Teste F & $2,68^{\text {ns }}$ & $0,34^{\text {ns }}$ & $0,05^{\text {ns }}$ & $2,61^{\mathrm{ns}}$ & $6,3^{*}$ & $3,54^{\mathrm{ns}}$ \\
\hline dms (Tukey, 5\%) & 32 & 105 & 86 & 90 & 88 & 51 \\
\hline \multicolumn{7}{|l|}{ Cultivar (C) } \\
\hline IAC-Tatu ST & $70 b$ & $283 b$ & $248 b$ & $299 a$ & $359 b$ & $191 b$ \\
\hline IAC-Caiapó & $296 a$ & $502 \mathrm{a}$ & $487 \mathrm{a}$ & $585 \mathrm{a}$ & $652 \mathrm{a}$ & $441 \mathrm{a}$ \\
\hline Teste F & $285 * *$ & $161 * *$ & $198 * *$ & $75,1 * *$ & $66,1 * *$ & $228 * *$ \\
\hline dms (Tukey, 5\%) & 32 & 38 & 38 & 75 & 82 & 38 \\
\hline \multicolumn{7}{|l|}{ Interação S x C } \\
\hline Teste F & $1,09^{\mathrm{ns}}$ & $5,8^{*}$ & $4,8^{*}$ & $0,05^{\mathrm{ns}}$ & $0,18^{\mathrm{ns}}$ & $3,16^{\mathrm{ns}}$ \\
\hline CV (\%) parcela & 11,9 & 17,4 & 15,4 & 13,3 & 11,3 & 10,5 \\
\hline CV (\%) subparcela & 17,8 & 10,8 & 11,3 & 18,3 & 17,5 & 12,8 \\
\hline
\end{tabular}

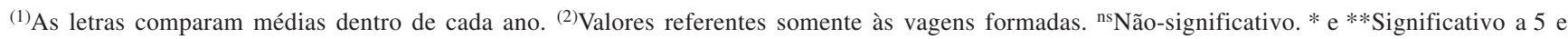
$1 \%$ de probabilidade, respectivamente.

Tabela 6. Índice de rendimento (IR) de grãos (\%), de duas cultivares de amendoim em diferentes sistemas de manejo do solo, sobre palhiço de cana crua, em Ribeirão Preto e Pindorama. Média de quatro repetições ${ }^{(1)}$.

\begin{tabular}{|c|c|c|c|c|c|c|c|}
\hline \multirow[t]{2}{*}{ Sistema (S) } & \multicolumn{6}{|c|}{ Ribeirão Preto } & \multirow{2}{*}{$\frac{\text { Pindorama }}{2000 / 2001}$} \\
\hline & $1999 / 2000$ & $2000 / 2001$ & $2001 / 2002$ & $2002 / 2003$ & $2003 / 2004$ & $2004 / 2005$ & \\
\hline Convencional & $62,4 \mathrm{~b}$ & 73,3 & 69,1 & $67,7 \mathrm{~b}$ & 70,9 & 69,0 & 68,1 \\
\hline Cultivo mínimo & $68,5 \mathrm{a}$ & 75,0 & 71,3 & $69,6 \mathrm{ab}$ & 70,3 & 63,0 & 63,5 \\
\hline Teste F & $11,3 * *$ & $2,9^{\text {ns }}$ & $1,1^{\mathrm{ns}}$ & $6,87 *$ & $2,25^{\mathrm{ns}}$ & $4,5^{\text {ns }}$ & $2,47^{\mathrm{ns}}$ \\
\hline dms (Tukey, 5\%) & 5,9 & 2,1 & 6,3 & 5,4 & 3,8 & 3,5 & 11,2 \\
\hline \multicolumn{8}{|l|}{ Cultivar (C) } \\
\hline IAC-Tatu ST & 66,6 & 73,8 & $67,1 b$ & 71,4 & $68,4 \mathrm{~b}$ & 67,2 & 62,8 \\
\hline IAC-Caiapó & 68,3 & 74,4 & $71,5 \mathrm{a}$ & 69,6 & $71,2 \mathrm{a}$ & 67,1 & 65,6 \\
\hline Teste F & $2,1^{\mathrm{ns}}$ & $0,91^{\mathrm{ns}}$ & $5,5^{*}$ & $0,24^{\mathrm{ns}}$ & $8,14 *$ & $0,01^{\mathrm{ns}}$ & $1,06^{\mathrm{ns}}$ \\
\hline dms (Tukey, 5\%) & 2,6 & 1,2 & 3,7 & 8,3 & 2,18 & 3,84 & 7,8 \\
\hline \multicolumn{8}{|l|}{ Interação S x C } \\
\hline Teste F & $0,5^{\text {ns }}$ & $0,21^{\mathrm{ns}}$ & $1,33^{\mathrm{ns}}$ & $0,03^{\mathrm{ns}}$ & $0,36^{\mathrm{ns}}$ & $2,35^{\mathrm{ns}}$ & $0,06^{\mathrm{ns}}$ \\
\hline CV (\%) parcela & 5,7 & 1,9 & 5,9 & 5,1 & 3,3 & 3,4 & 11,5 \\
\hline CV (\%) subparcela & 4,2 & 1,7 & 5,8 & 12,7 & 3,4 & 6,2 & 13,3 \\
\hline
\end{tabular}

${ }^{(1)}$ As letras comparam médias em cada ano. ns Não-significativo. * e **Significativo a 5 e $1 \%$ de probabilidade, respectivamente. 
(Grichar \& Smith, 1991; Wright \& Porter, 1991; Grichar, 1998; Jordan et al., 2001), as quais relatam perdas de $3 \%$ no rendimento de grãos nos sistemas conservacionistas.

Quanto ao estande final de plantas (Tabela 7), constatou-se diminuição significativa nos sistemas conservacionistas somente nos ensaios semeados em janeiro. O menor estande final observado no ensaio de Pindorama pode ser uma das causas para menor produção de vagens nos sistemas conservacionistas. Todavia, Rahmianna et al. (2000) observaram que, no plantio direto de amendoim, as falhas na emergência chegam a 11,7 e $7,3 \%$, respectivamente, quando realizado com palha e sem palha, aspecto que atribuem como causador das menores produções em sistemas conservacionistas. Em períodos de deficiência hídrica, a cultura do amendoim pode ser favorecida no sistema plantio direto. Após 10 dias sem chuvas maiores que $5 \mathrm{~mm}$, o sistema plantio direto apresentava maiores conteúdos de água no solo, na profundidade de $0,00-0,12 \mathrm{~m}$, entre 7 e $16 \%$ a mais que no convencional (Figura 3).

Na profundidade de $0,00-0,20 \mathrm{~m}$, no sistema cultivo mínimo, ocorreu redução significativa na umidade. Medidas efetuadas aos 20 dias da emergência demonstraram que quanto maior a quantidade de palhiço, maior o conteúdo de água no solo (Tabela 8). Com o fechamento da cultura, as diferenças entre sistemas não

Tabela 7. Estande final de plantas de amendoim em diferentes sistemas de manejo do solo sobre palhada de cana crua, em Ribeirão Preto e Pindorama ${ }^{(1)}$.

\begin{tabular}{|c|c|c|c|c|c|c|c|}
\hline \multirow[t]{2}{*}{ Sistema (S) } & \multicolumn{6}{|c|}{ Ribeirão Preto } & \multirow{2}{*}{$\begin{array}{l}\text { Pindorama } \\
2000 / 2001\end{array}$} \\
\hline & $1999 / 2000$ & $2000 / 2001$ & $2001 / 2002$ & $2002 / 2003$ & $2003 / 2004$ & $2004 / 2005$ & \\
\hline Convencional & $12,2 \mathrm{a}$ & $15,1 \mathrm{a}$ & 12,8 & 11,6 & 16,4 & 18,3 & $12,0 \mathrm{a}$ \\
\hline Cultivo mínimo & $10,9 b$ & $14,8 \mathrm{ab}$ & 12,3 & 10,5 & 14,3 & 18,6 & $9,6 \mathrm{~b}$ \\
\hline Plantio direto & $10,7 \mathrm{~b}$ & $14,4 \mathrm{~b}$ & 12,5 & 10,1 & 15,5 & 18,3 & $9,3 \mathrm{~b}$ \\
\hline Teste F & $22,1 * *$ & $4,8^{\mathrm{ns}}$ & $0,53^{\text {ns }}$ & $4,68^{\mathrm{ns}}$ & $4,08^{\mathrm{ns}}$ & $0,12^{\text {ns }}$ & $31,1 * *$ \\
\hline dms (Tukey, 5\%) & 0,7 & 0,71 & 1,49 & 1,6 & 2,3 & 2,75 & 0,9 \\
\hline \multicolumn{8}{|l|}{ Cultivar (C) } \\
\hline IAC-Tatu ST & $15,6 \mathrm{a}$ & $17,6 a$ & $15,7 \mathrm{a}$ & $12,7 \mathrm{a}$ & $20,4 a$ & $22,0 \mathrm{a}$ & $13,1 \mathrm{a}$ \\
\hline IAC-Caiapó & $6,9 \mathrm{~b}$ & $11,9 \mathrm{~b}$ & $9,3 b$ & $8,8 \mathrm{~b}$ & $10,3 \mathrm{~b}$ & $14,6 \mathrm{~b}$ & $7,3 \mathrm{~b}$ \\
\hline Teste F & $2.227 * *$ & $405^{* *}$ & $433 * *$ & $138 * *$ & $298 * *$ & $69,3 * *$ & $86,5 * *$ \\
\hline dmsTukey (5\%) & 0,41 & 0,63 & 0,7 & 0,7 & 1,3 & 2,0 & 1,4 \\
\hline \multicolumn{8}{|l|}{ Interação S x C } \\
\hline Teste F & $0,62^{\mathrm{ns}}$ & $4,18^{\mathrm{ns}}$ & $4,8^{*}$ & $1,63^{\mathrm{ns}}$ & $1,98^{\mathrm{ns}}$ & $0,59^{\text {ns }}$ & $0,34^{\mathrm{ns}}$ \\
\hline CV (\%) parcela & 4,2 & 3,1 & 7,7 & 9,5 & 9,7 & 9,75 & 5,8 \\
\hline CV (\%) subparcela & 3,9 & 4,7 & 5,9 & 7,4 & 9,3 & 11,8 & 15,1 \\
\hline
\end{tabular}

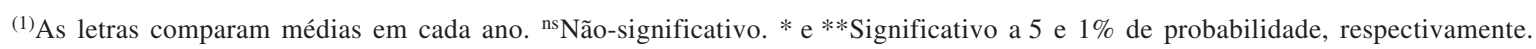
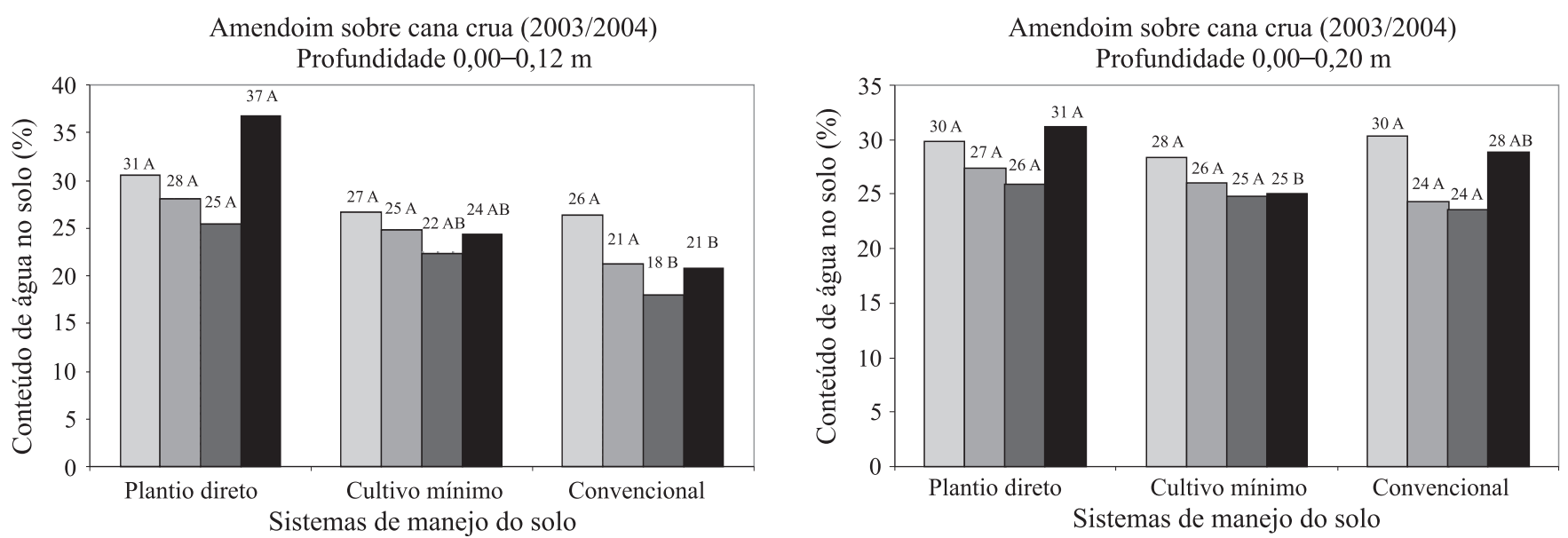

$16 / 12 / 2003 \quad \square 18 / 12 / 2003 \quad \square 19 / 12 / 2003 \quad \square 22 / 12 / 2003$

Figura 3. Conteúdo volumétrico de água (\%) no solo nas profundidades de 0,00-0,12 e 0,00-0,20 m, em três manejos de solo sobre cana crua, em Ribeirão Preto, 2003-2004. Média de 24 repetições. Letras maiúsculas comparam médias em cada data de avaliação, pelo teste de Tukey, a 5\% de probabilidade. 
Tabela 8. Conteúdo volumétrico (\%) de água no solo, nas camadas de 0-12 e 0-20 cm de profundidade, de acordo com os sistemas de manejo do solo e posição de amostragem (linha e entrelinha), em diferentes fases de desenvolvimento das cultivares de amendoim IAC-Tatu ST e IAC-Caiapó, na renovação de cana crua, em Ribeirão Preto, 2003/2004. Média de oito repetições.

\begin{tabular}{|c|c|c|c|c|}
\hline \multirow[t]{2}{*}{ Sistema (S) } & \multirow{2}{*}{$\frac{30 / 12 / 2003}{0,00-0,12 \mathrm{~m}}$} & \multicolumn{2}{|c|}{$12 / 2 / 2004$} & \multirow{2}{*}{$\begin{array}{c}8 / 3 / 2004 \\
0,00-0,12 \mathrm{~m}\end{array}$} \\
\hline & & $0,00-0,12 \mathrm{~m}$ & $0,00-0,20 \mathrm{~m}$ & \\
\hline Convencional & $22 \mathrm{c}$ & 29 & 45 & 34 \\
\hline Cultivo mínimo & $29 b$ & 28 & 44 & 34 \\
\hline Plantio direto & $38 \mathrm{a}$ & 29 & 45 & 30 \\
\hline Teste F & $48,7 * *$ & $0,28^{\text {ns }}$ & $0,4^{\mathrm{ns}}$ & $1,69^{\mathrm{ns}}$ \\
\hline ms (Tukey, $5 \%$ ) & 4,4 & 5,6 & 6,3 & 6,9 \\
\hline \multicolumn{5}{|l|}{ Posição (P) } \\
\hline Entrelinha & $36 a$ & $33 a$ & $49,5 \mathrm{a}$ & $36 a$ \\
\hline Linha de semeadura & $23 \mathrm{~b}$ & $25 \mathrm{~b}$ & $39,8 \mathrm{~b}$ & $29 \mathrm{~b}$ \\
\hline Teste F & $29,2 * *$ & $46,2 * *$ & $93,6^{* *}$ & $48,4^{* *}$ \\
\hline ms (Tukey, 5\%) & 5,0 & 2,5 & 2,1 & 2,2 \\
\hline \multicolumn{5}{|l|}{ Interação S x P } \\
\hline Teste F & $1,2^{\mathrm{ns}}$ & $2,0^{\mathrm{ns}}$ & $9,6 * *$ & $2,4^{\mathrm{ns}}$ \\
\hline $\mathrm{CV}(\%)$ sistemas & 15,9 & 22,3 & 15,9 & 23,2 \\
\hline CV (\%) posição & 28,2 & 14,7 & 28,2 & 11,3 \\
\hline
\end{tabular}

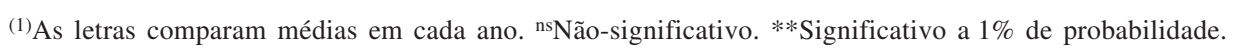

foram significativas. Ramakrishna et al. (2006) concluíram que o cultivo de amendoim sobre palhada proporciona, em período seco, redução de $22 \%$ nas perdas de água no solo, o que corrobora os resultados obtidos neste trabalho.

\section{Conclusões}

1. Não há diferença entre os sistemas de manejo conservacionistas e convencional, para renovação de cana crua em Latossolo, na produção de vagens e grãos e no número de estruturas reprodutivas de amendoim.

2. Há interação entre cultivar de amendoim e manejo de solo, e a cultivar IAC-Caiapó é a menos responsiva às diferenças de manejo de solo.

3. Em sistemas conservacionistas ocorre redução no estande final de plantas em época de semeadura extemporânea.

4. O índice de rendimento de grãos aumenta de 6,5 a $9 \%$ no sistema plantio direto, em relação ao convencional.

5. No sistema plantio direto sobre palhiço de cana, o conteúdo de água no solo na profundidade de $0,00-0,12 \mathrm{~m}$ pode ser até $16 \%$ maior que no convencional em períodos de veranico.

\section{Referências}

BOLONHEZI, D.; SANTOS, R. C. dos; GODOY, I.J. de. Manejo cultural do amendoim. In: SANTOS, R.C. dos. (Ed.). O agronegócio do amendoim no Brasil. Campina Grande: Embrapa Algodão, 2005. p.193-244.
COLVIN, D.L.; BRECKE, B.J. Peanut cultivar response to tillage systems. Peanut Science, v.15, p.21-24, 1988.

COLVIN, D.L.; BRECKE, B.J.; WHITTY, E.B. Tillage variable for peanut production. Peanut Science, v.15, p.94-97, 1988.

EMBRAPA. Centro Nacional de Pesquisa de Solos. Sistema brasileiro de classificação de solos. Brasília: Embrapa-Serviço de Produção da Informação; Rio de Janeiro: Embrapa Solos, 1999. 412p.

GRICHAR, W.J. Long term effects of three tillage systems on peanut grade, yield, and stem rot development. Peanut Science, v.25, p.5962, 1998.

GRICHAR, W.J.; BOSWELL, T.E. Comparison of no-tillage, minimum, and full tillage cultural practices on peanuts. Peanut Science, v.4, p.101-103, 1987.

GRICHAR, W.J.; SMITH, O.D. Effects of tillage systems on Southern blight and pod yield of five runner peanut genotypes. Peanut Science, v.18, p.144-147, 1991.

GRICHAR, W.J.; SMITH, O.D. Interaction of tillage and cultivars in peanut production systems. Peanut Science, v.19, p.95-98, 1992.

HARTZOG, D.L.; ADAMS, J.F. Reduced tillage for peanut production. Soil \& Tillage Research, v.14, p.85-90, 1989.

JORDAN, D.L.; BARNES, J.S.; BOGLE, C.R.; NADERMAN, G.C.; ROBERSON, G.T.; JOHNSON, P.D. Peanut response to tillage and fertilization. Agronomy Journal, v.93, p.1125-1130, 2001.

PORTER, D.M.; WRIGHT, F.S. Early leafspot of peanuts: effect of conservation tillage practices on disease development. Peanut Science, v.18, p.76-79, 1991.

RAHMIANNA, A.A.; ADISARWANTO, T.; KIRCHHOF, G.; SO, H.B. Crop establishment of legumes in rainfed lowland rice-based cropping systems. Soil \& Tillage Research, v.56, p.67-82, 2000.

RAMAKRISHNA, A.; TAM, H.M.; WANI, S.P.; LONG, T.D. Effect of mulch on soil temperature, moisture, weed infestation and yield of groundnut in northern Vietnam. Field Crops Research, v.95, p.115-125, 2006. 
RIPOLI, T.C.C.; RIPOLI, M.L.C. Biomassa de cana-de-açúcar: colheita, energia e ambiente. Piracicaba: Barros \& Marques Editoração Eletrônica, 2004. 302 p.

RUDORFF, B.F.T.; BERKA, L.M.S.; XAVIER, A.C.; MOREIRA, M.A.; DUARTE,V.; ROSA, V.G.C.; SHIMABUKURO, Y.E. Estimativa de área plantada com cana-de-açúcar em municípios do Estado por meio de imagens de satélites e técnicas de geoprocessamento: ano safra 2003/2004. São José dos Campos: Instituto Nacional de Pesquisas Espaciais, 2004. 47p.

SHOLAR, J.; MOZINGO, R.W.; BEASLEY JUNIOR, J. Peanut cultural practices. In: PATEE, H.E.; STALKER, H.T. (Ed.). Advances in peanut science. Stillwater: American Peanut Research and Education Society, 1995. p.354-382.
TASSO JÚNIOR, L.C. Cultura da soja, milho e amendoim sob diferentes sistemas de manejo do solo em área com palha residual de colheita mecanizada de cana crua. 2003. 154p. Dissertação (Mestrado). Universidade Estadual Paulista, Jaboticabal. WRIGHT, F.S. Alternate tillage practices for peanut production in Virginia. Peanut Science, v.18, p.9-11, 1991.

WRIGHT, F.S.; PORTER, D.M. Digging date and conservational tillage influence on peanut production. Peanut Science, v.18, p.7275, 1991.

WRIGHT, F.S.; PORTER, D.M.; POWELL, N.L.; ROSS, B.B. Irrigation and tillage effects on peanut yield in Virginia. Peanut Science, v.13, p.89-92, 1986.

Recebido em 7 de novembro de 2006 e aprovado em 30 de maio de 2007 